\title{
Root Coverage Grafting Comparing Placental Derived Membrane to Acellular Dermis Matrix: A Case Series
}

Stephen C. Wallace*

2525 Delaney Road, Wilmington, North Carolina 28403, USA

\begin{abstract}
Gingival recession remains a widespread finding in the general patient population. A placenta-derived membrane has been introduced for treatment of recession defects but it has not been studied in comparison to acellular dermis matrix. The purpose of this case series was to evaluate results of coronally advanced flap surgery using placentaderived membranes (PM) compared to acellular dermis matrix (ADM). A split-mouth design was used in this study with 60 contralateral sites in 8 patients with Miller Class I or II recession sites.

30 sites were treated with placenta-derived membranes and were compared to 30 sites treated with acellular dermal matrix, both done with a coronally positioned flap technique. Enamel matrix derivative was applied to all root surfaces after root planing and treatment with EDTA.

Clinical parameters recorded at baseline and after three months were vertical recession (VR), probing depth (PD), clinical attachment level (CAL) and keratinized tissue width (KT).

Results: Both groups showed significant recession coverage, decreased probing depth, increased clinical attachment gain but minimal increased width of keratinized gingiva.

The percentage of root coverage was $84 \%$ for the ADM-treated sites, and $57 \%$ for the PM sites. Clinical attachment gain was $2.4 \mathrm{~mm}$ for PM and $3.0 \mathrm{~mm}$ for ADM. The differences in vertical root coverage were statistically significant.

Based on the results of this study, both materials were effective in gaining vertical root coverage and increasing clinical attachment, with the acellular dermis matrix material showing a statistically significant greater amount of root coverage.
\end{abstract}

\section{Introduction}

The prevalence of gingival recession in the general population has been reported to be $25 \%$ [1]. Numerous techniques have been used to treat recession and attachment loss. These include laterally positioned flaps [2], free gingival grafts [3-5], subepithelial grafts [6], barrier membranes [7-9] and acellular dermal matrix [10]. The 1996 review of multiple root-coverage techniques by Wennstrom [11] reported root coverage using subepithelial connective tissue grafts ranging from $50 \%$ to $98 \%$, with an average of $89 \%$, so a wide variation in root coverage results has been reported in published studies.

A new material, a placental tissue-derived membrane was introduced for root coverage in treatment of gingival recession. The purpose of this case series is to compare results of perioplastic surgery for root coverage using the placental-derived membrane and acellular dermis matrix.

\section{Materials and Methods}

All patients received verbal and written instructions for home care and signed a consent form before surgery. Selection criteria included: patients 18 years of age or greater, no active periodontal disease, nonsmokers, no uncontrolled diabetes, no history of systemic conditions that could interfere with normal healing and recovery. Sites treated were selected randomly for split-mouth treatment of bilateral recession defects with either placental-derived membrane or acellular dermis matrix. All measurements and treatment were done by the same clinical investigator. A North Carolina periodontal probe (Hu-Friedy Inc, Chicago, IL) was used to record measurements to the nearest $0.5 \mathrm{~mm}$.

Each patient was draped and the face scrubbed with povidone iodine $7.5 \%$ solution (Cardinal Health: McGaw Park, IL). Each surgery was done with monitored intravenous anesthesia using an automatic pulse oximeter displaying heart rate, electrocardiogram, oxygen saturation, and blood pressure. One gram of Cefazolin for injection (Cura Pharmaceuticals, Eatontown, NJ) was diluted with sterile water for injection and placed into a $500 \mathrm{cc}$ sterile $0.9 \%$ saline bag, unless cephalosporin sensitivity was reported. In this event, $200 \mathrm{mg}$ of intravenous Cipro (Bayer Pharmaceutical Corporation, West Haven, CT) was placed in the $500 \mathrm{cc}$ i.v. solution. All of the i.v. fluid was given to administer the antibiotic contents. An intravenous line was obtained with a 23 gauge butterfly needle (Terumo Medical Corporation, Elkton, Md.) and infusion was continuous with $500 \mathrm{cc} 0.9 \%$ saline. Sedation was initiated with slow intravenous administration of 50 mg. diphenhydramine (Baxter Healthcare Corporation, Deerfield, IL), followed by $50 \mathrm{mg}$. of Demerol (Hospira, Lake Forest, IL) and 8 mg. of dexamethasone (American Regent Corporation, Shirley, NY) slowly given. Then midazolam $5 \mathrm{mg} / \mathrm{cc}$ (Parenta Pharmaceuticals, West Columbia, SC) and Propofol 10mg/cc (Parenta Pharmaceuticals, West Columbia, SC) were given by titration to induce and maintain the desired level of conscious sedation. Local anesthesia was obtained by infiltration only with $2 \%$ lidocaine with 1:100,000 epinephrine.

\section{Surgical Procedure}

In each recession site, inverse bevel incisions with two vertical

*Corresponding author: Stephen C. Wallace, 2525 Delaney Road, Wilmington, North Carolina 28403, USA, E-mail: scwperio@drstevewallace.com

Received March 28, 2012; Accepted June 06, 2012; Published June 12, 2012

Citation: Wallace SC (2012) Root Coverage Grafting Comparing Placenta Derived Membrane to Acellular Dermis Matrix: A Case Series. Dentistry 2:137. doi:10.4172/2161-1122.1000137

Copyright: () 2012 Wallace SC. This is an open-access article distributed under the terms of the Creative Commons Attribution License, which permits unrestricted use, distribution, and reproduction in any medium, provided the original author and source are credited. 


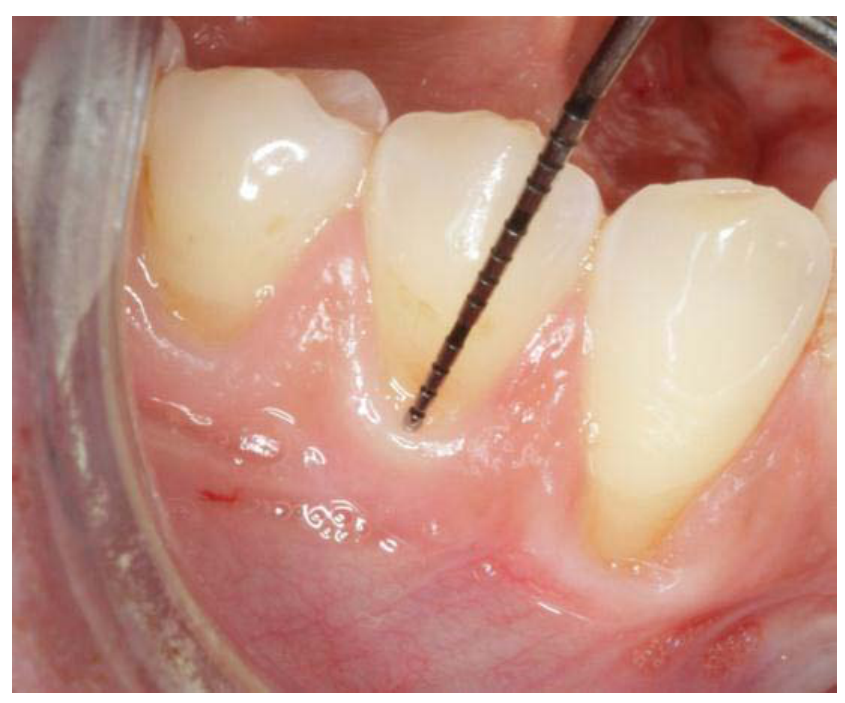

Figure 1: Presurgery placental membrane.

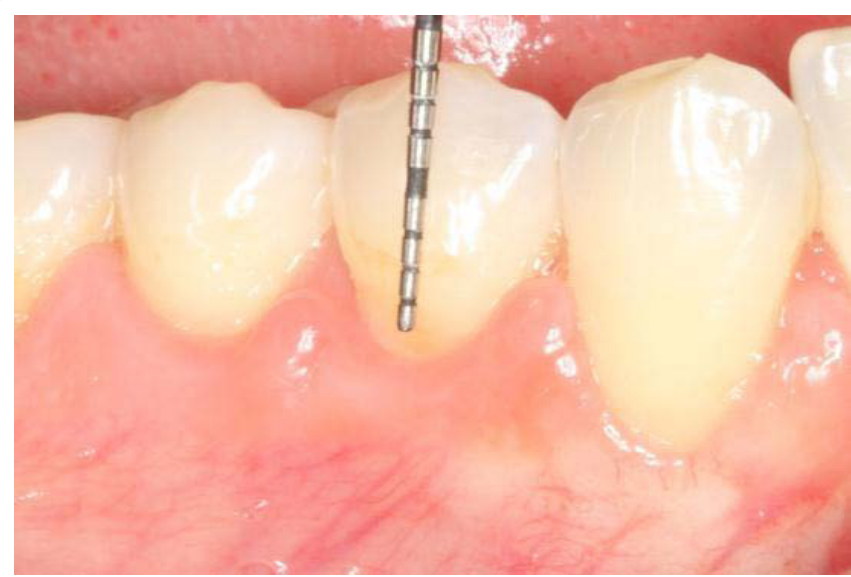

Figure 2: 4 months post-surgery placental membrane.

release incisions were made with a \#15-c \$† blade extending at least one tooth past each recession site. The facial of each adjacent papilla was de-epithelialized to promote reattachment of the flap.

Split-thickness flaps were elevated a minimum of $10 \mathrm{~mm}$ past the mucogingival junction. Full-thickness incisions were then used to release the periosteum and passively position flaps two to three millimeters coronal to the cemento-enamel junction [9].

Root surfaces were thoroughly planed to remove any contaminants and to flatten the facial contour, then treated with EDTA for 1 minute and rinsed with sterile saline. Emdogain was applied to dry root surfaces prior to placement of the dehydrated placental membrane. The membranes were cut to cover the treated root surfaces from mesial to distal, and were extended a minimum of 5 millimeters apically covering the crestal bone. The placenta-derived membranes were cut dry and not hydrated before application to the prepared root surfaces. No sutures were used to secure placental membranes in position as they adhered to the root surface without movement. Acellular dermis matrix membranes \pm 0.5 to $0.8 \mathrm{~mm}$ in thickness, were also cut to approximately 10 by $10 \mathrm{~mm}$ and hydrated for 30 minutes in two different sterile saline solutions. The membranes were secured around the teeth with 6-0 polygalactin suture (Vicryl, Johnson \& Johnson, Somerville, NJ.) placed with a sling technique to minimize movement of the membrane after surgery.

Flaps were secured with 6-0 polygalactin suture in a coronally advanced position so as to completely cover the membranes. Light pressure was applied to each site after suturing to adapt the flap closely and achieve hemostasis. Medicines prescribed after the surgery were $0.12 \%$ chlorhexidine gluconate (Peridex Omnipharma, West Palm Beach, FL) antibacterial rinses twice daily, cephalosporin 500 mg oral capsules, one capsule three times a day, Medrol Dosepak (Pfizer Pharmaceuticals, Kirkland, Quebec, Canada), and meprozine (Qualitest Pharmaceuticals, Huntsville, AL) as needed for discomfort. Sutures were removed after 2 weeks. Follow-up visits were at 6 weeks and then at 4 months for recording of clinical measurements.

\section{Results}

The end results expected were increased root coverage, increased clinical attachment and increased width of keratinized gingiva.

For the sites treated with the acellular dermis matrix, the vertical recession reduction was $85 \%$, the increase in clinical attachment was $3.0 \mathrm{~mm}$, probing depth decreased by $0.8 \mathrm{~mm}$ and keratinized tissue width increase was $0.4 \mathrm{~mm}$. Figures 1 and 2 show the pretreatment and post-surgery appearance of \#20,\#21 and \#22 treated with acellular dermis in a split-mouth study design after 4 months

For the sites treated with placenta-derived membranes, the vertical recession reduction was $57 \%$, increase in clinical attachment was 2.4 $\mathrm{mm}$ with a reduction in probing depth of $0.8 \mathrm{~mm}$, keratinized tissue width increase was $0.2 \mathrm{~mm}$. Figures 3 and 4 show the same patient as in Figures 1 and 2, pre-treatment and post-surgery appearance of \#27, \#28 and \#29 treated with placental membrane placement after 4 months.

The difference in vertical root coverage gained was statistically significant.

\section{Discussion}

Root coverage obtained for the acellular dermis matrix group compared favorably with the recent report by Barker et al. [12] who reported $81.4 \%$ to $83.4 \%$ with two different acellular dermis materials used for root coverage grafting.

There are many advantages in use of an allograft soft tissue material

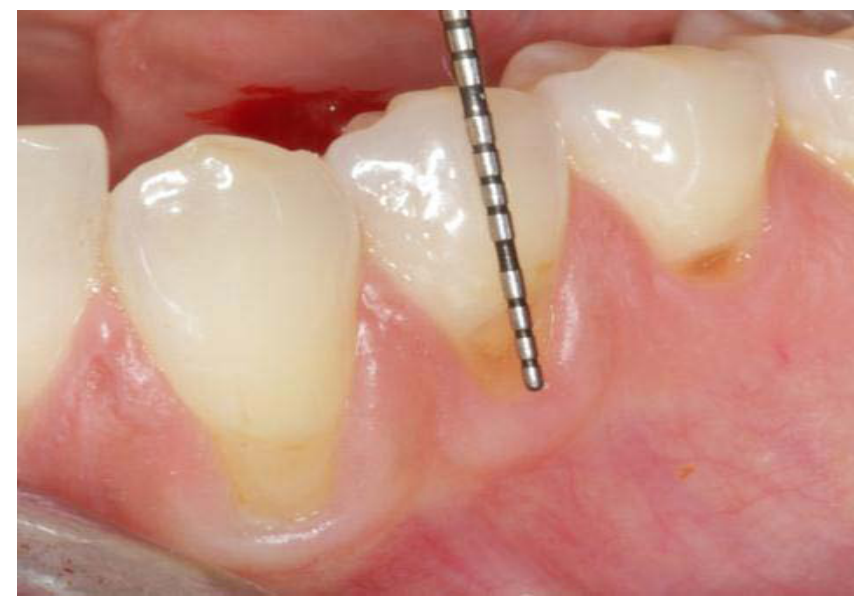

Figure 3: Presurgery acellular dermis. 


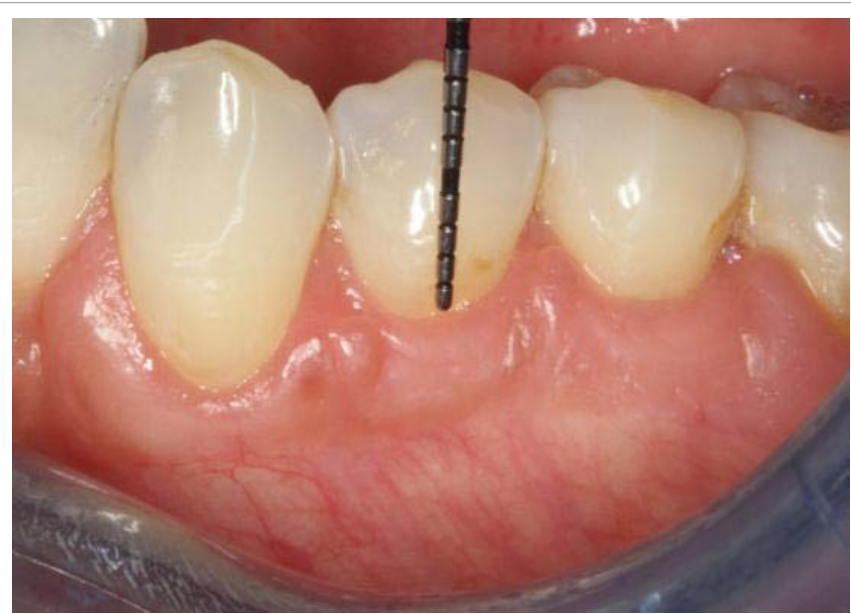

Figure 4: 4 months post-surgery acellular dermis.

instead of harvested palatal grafts. The material is unlimited in quantity used, so patients with multiple recession sites in different quadrants, or all quadrants, can be treated in a single surgery. No surgical stents are needed, so this eliminates another technical procedure requiring impressions and laboratory fabrication. Also eliminated is the need for suturing palatal sites and bleeding control during and after palatal harvest.

Patients have reduced post-surgery morbidity without a palatal harvest, as the epithelium over a denuded palatal donor site regrows at the rate of 0.5 to $1.0 \mathrm{~mm}$ per day, resulting in extended discomfort [13]

Studies report similar histology of the attachment between connective tissue and acellular dermis matrix, so this means acellular dermis does not form simply a long junctional epithelium attachment to root surfaces [14] Other studies also reported no significant difference between acellular dermis matrix and harvested autogenous connective tissue grafts with respect to root coverage, keratinized tissue formation, probing depths or clinical attachment levels [15].

Tunneling has been shown not to be necessary for results equivalent to coronally positioned flaps as recent publications have reported $95 \%$ root coverage with coronally positioned flaps compared to tunneling results of $78 \%$ [16]. Other disadvantages of tunneling are time required and technical difficulty [17].

There are a number of contributory factors affecting the amount of root coverage attained with coronally positioned flaps with acellular dermis, connective tissue and enamel matrix derivative alone. These multiple factors have to be taken into account in addition to the comparatively simplistic Miller classifications of soft tissue recession defects. Tissue thickness [18] has been shown to influence the amount of root coverage obtained as the thicker tissue may reflect thicker underlying bone support. Thicker marginal gingiva is less likely to show dehiscence and collapse due to the increased collagenous content and keratinized surface. Cervical defect depth and cervical defect width are correlated with reduced numbers of sites that will result in complete root coverage [19]. Vertical recession depth is correlated with lack of full root coverage when treatment is done with coronally advanced flaps utilizing enamel matrix derivative [20].

Reports also indicate that we see minimal post-surgical recession in anterior esthetic areas where split thickness flap techniques are used, indicating that the blood supply is greater with the periosteum intact [21].
Prato et al, showed that there was statistically lower root coverage with higher flap tension after suturing coronally advanced flaps, however, passively positioning of released flaps to or past the CEJ was associated with greater root coverage [22]. Papilla width and a height of at least $5 \mathrm{~mm}$ adjacent to recession sites are associated with increased root coverage [23]. Excessive root convexity and root prominence may negatively affect the amount of root coverage gained with soft tissue grafts [24]. Root coverage surgery with rotated teeth will tend to result in a portion of the root surface left uncovered [25].

Within the same patient, teeth with abfractions presented more attachment loss than those without abfractions [26].

Utilization of enamel matrix derivative with coronally positioned flaps with and without soft tissue grafts promotes root coverage, thickens overlying gingival tissue, decreases dehiscence complications and reduces post-surgery pain and swelling [27-29].

Further long term studies are needed to confirm our preliminary findings and investigate the contributory factors that can influence graft surgery for root coverage with allograft membrane tissue using coronally advanced flaps.

\section{Conclusions}

Within the limits of this case series, the results show very limited root coverage from use of a placenta-derived membrane compared to acellular dermis matrix.

\section{Acknowledgment}

This study was supported in part by Biohorizons Inc. who provided AlloDerm acellular dermis matrix product, and by Snoasis Medical who provided BioCover placental membrane.

\section{References}

1. Albandar JM, Kingman A (1999) Gingival recession, gingival bleeding, and dental calculus in adults 30 years of age and older in the United States, 19881994. J Periodontol 70: 30-43.

2. Grupe HE, Warren RF (1956) Repair of gingival defects by a sliding flap operation. J Periodontol 27: 290-295.

3. Nabers JM (1966) Free gingival grafts. Periodontics 4: 243-245.

4. Miller PD Jr. (1982) Root coverage using a free soft tissue autograft following citric acid application. Part 1: Technique. Int J Periodontics Restorative Dent 2: $65-70$.

5. Holbrook T, Ochsenbein C (1983) Complete coverage of the denuded root surface with a one-stage gingival graft. Int J Periodontics Restorative Dent 3 : 8-27.

6. Langer B, Langer $L$ (1985) Subepithelial connective tissue graft technique for root coverage. J Periodontol 56: 715-720.

7. Tinti C, Vincenzi G, Cortellini P, Pini Prato G, Clauser C (1992) Guided tissue regeneration in the treatment of human facial recession. A 12-case report. J Periodontol 63: 554-560.

8. Prato GP, Clauser C, Magnani C, Cortellini P (1995) Resorbable membrane in the treatment of human buccal recession: a nine-case report. Int J Periodontics Restorative Dent 15: 258-267.

9. Roccuzzo M, Lungo M, Corrente G, Gandolfo S (1996) Comparative study of a bioresorbable and a non-resorbable membrane in the treatment of human buccal gingival recessions. J Periodontol $67: 7-14$

10. Harris RJ (2000) A comparative study of root coverage obtained with an acellula dermal matrix versus a connective tissue graft: results of 107 recession defects in 50 consecutively treated patients. Int J Periodontics Restorative Dent 20 51-59.

11. Wennstrom JL (1996) Mucogingival therapy. Ann Periodontol 1: 671-701.

12. Barker TS, Cueva MA, Rivera-Hidalgo F, Beach MM, Rossmann JA, et al. 
Citation: Wallace SC (2012) Root Coverage Grafting Comparing Placental Derived Membrane to Acellular Dermis Matrix: A Case Series. Dentistry 2:137. doi:10.4172/2161-1122.1000137

(2010) A comparative study of root coverage using two different acellular dermal matrix products. J Periodontol 81: 1596-1603.

13. Engler WO, Ramfjord SP, Hiniker JJ (1966) Healing following simple gingivectomy. A tritiated thymidine radioautographic study. I. Epithelialization. J Periodontol 37: 298-308.

14. Harris RJ (2000) A comparative study of root coverage obtained with an acellular dermal matrix versus a connective tissue graft: Results of 107 recession defects in 50 consecutively treated patients. Int J Periodontics Restorative Dent $20: 51-59$

15. Gapski R, Parks CA, Wang HL (2005) Acellular dermal matrix for mucogingival surgery: a meta-analysis. J Periodontol 76: 1814-1822.

16. Papageorgakopoulos G, Greenwell H, Hill M, Vidal R, Scheetz JP (2008) Root coverage using acellular dermal matrix and comparing a coronally positioned tunnel to a coronally positioned flap approach. J Periodontol 79: 1022-1030.

17. Modaressi M, Wang HL (2009) Tunneling procedure for root coverage using acellular dermal matrix: a case series. Int J Periodontics Restorative Dent 29: 395-403.

18. Hwang D, Wang HL (2006) Flap thickness as a predictor of root coverage: a systematic review. J Periodontol 77: 1625-1634.

19. Santamaria MP, Ambrosano GM, Casati MZ, Nociti FH Jr, Sallum AW, et al (2010) The influence of local anatomy on the outcome of treatment of gingival recession associated with non-carious cervical lesions. J Periodontol 81: 10271034.

20. Nieri M, Rotundo R, Franceschi D, Cairo F, Cortellini P, et al. (2009) Factors affecting the outcome of the coronally advanced flap procedure: a Bayesian network analysis. J Periodontol 80: 405-410.

21. Trombelli L, Farina R, Franceschetti G, Calura G (2009) Single-flap approach with buccal access in periodontal reconstructive procedures. J Periodontol 80 : 353-360.

22. Pini Prato G, Pagliaro U, Baldi C, Nieri M, Saletta D, et al. (2000) Coronally advanced flap procedure for root coverage. Flap with tension versus flap without tension: a randomized controlled clinical study. J Periodontol 71: 188201.

23. Haghighati F, Mousavi M, Moslemi N, Kebria MM, Golestan B (2009) A comparative study of two root-coverage techniques with regard to interdental papilla dimension as a prognostic factor. Int J Periodontics Restorative Dent 29: 179-189.

24. Miller PD Jr. (1987) Root coverage with the free gingival graft. Factors associated with incomplete coverage. J Periodontol 58: 674-681.

25. Zucchelli G, Testori T, De Sanctis M (2006) Clinical and anatomical factors limiting treatment outcomes of gingival recession: a new method to predetermine the line of root coverage. J Periodontol 77: 714-721.

26. Reyes E, Hildebolt C, Langenwalter E, Miley D (2009) Abfractions and attachment loss in teeth with premature contacts in centric relation: clinical observations. J Periodontol 80: 1955-1962.

27. Castellanos A, de la Rosa M, de la Garza M, Caffesse RG (2006) Ename matrix derivative and coronal flaps to cover marginal tissue recessions. J Periodontol 77: 7-14

28. Cueva MA, Boltchi FE, Hallmon WW, Nunn ME, Rivera-Hidalgo F, et al. (2004) A comparative study of coronally advanced flaps with and without the addition of enamel matrix derivative in the treatment of marginal tissue recession. $J$ Periodontol 75: 949-956.

29. McGuire MK, Nunn M (2003) Evaluation of human recession defects treated with coronally advanced flaps and either enamel matrix derivative or connective tissue. Part 1: Comparison of clinical parameters. J Periodontol 74: 1110-1125. 